\title{
EL CHISME COMO GÉNERO DISCURSIVO \\ CONTESTATARIO EN LA SEGUA. COMEDIA EN TRES ACTOS CON PRÓLOGO Y ESTRAMBOTE INSPIRADA REMOTAMENTE EN UN RELATO DE ANASTASIO ALFARO \\ Irene González Muñoz
}

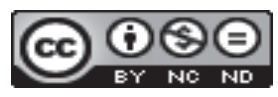

Doi: https://doi.org/10.15517/rfl.v46iExt..43631

URL: https://revistas.ucr.ac.cr/index.php/filyling/index 



\title{
EL CHISME COMO GÉNERO DISCURSIVO CONTESTATARIO EN LA SEGUA. COMEDIA EN TRES ACTOS CON PRÓLOGO Y ESTRAMBOTE INSPIRADA REMOTAMENTE EN UN RELATO DE ANASTASIO ALFARO
}

\author{
GOSSIP AS AN ANTI-ESTABLISHMENT DISCURSIVE \\ GENRE IN LA SEGUA. COMEDIA EN TRES ACTOS CON \\ PRÓLOGO Y ESTRAMBOTE INSPIRADA REMOTAMENTE EN \\ UN RELATO DE ANASTASIO ALFARO
}

Irene González Muñoz

\begin{abstract}
RESUMEN
Tomando como base las propuestas de L. Hoeck y G. Genette sobre el título como programador de lectura, así como los postulados teóricos de M. Bajtín sobre los géneros discursivos y de Y. Lotman sobre la literatura como sistema modelizante secundario, en el presente artículo se propone un acercamiento a la comedia La Segua, de Alberto Cañas, fundamentado en dos de sus elementos estructurantes: el prólogo y el estrambote. Según nuestra propuesta, el (pre)texto de la leyenda de la segua cumple una función dilatoria en el proceso de significación de esta comedia, pues al plantearse en el título la frase inicial: 'la segua', la lectura suele centrarse más en la idea de la posible re-creación de la leyenda y se obvia la segunda proposición de índole genérica, que conforma el título completo, y que posibilita otro eje de lectura, tal y como se plantea en el presente acercamiento.

Palabras clave: literatura costarricense; teatro; Alberto Cañas; crítica literaria; géneros discursivos.
\end{abstract}

\begin{abstract}
According to L. Hoeck and G. Genette's considerations of the title as an element programming the reading process, as well as to M. Bajtin's theoretical approach on discursive genres, and to Y. Lotman's approach on literature as a secondary modelling system, this article proposes a new perspective at the comedy La Segua, written by Alberto Cañas, based on two of its structural elements: the prologue and the extra lines. According to our approach, the (pre)text of the legend of La Segua plays a delaying role in the significance process of the comedy, considering the initial phrase of the title: "la segua", the reading centers on the possible recreation of the legend and omits the second approach of a generic nature that constitutes the entire title, and that enables a different point of view of the reading, as set out in this proposal.

Keywords: Costa Rican literature; theater; Alberto Cañas; literary criticism; discursive genres.
\end{abstract}

\footnotetext{
M. L. Irene González Muñoz. Profesora de la Escuela de Filología, Lingüística y Literatura, Universidad de Costa Rica. San José, Costa Rica.

Correo electrónico: irenego123@hotmail.com
} 
La Segua. Comedia en tres actos con prólogo y estrambote inspirada remotamente en un relato de Anastasio Alfaro (1967 / 1979), escrita por Alberto Cañas Escalante, se ambienta en Cartago, en la época colonial, de acuerdo con lo apuntado en la didascalia inicial, en el año "mil setecientos y pico", y trata sobre los avatares de las relaciones amorosas de Encarnación Sancho, quien es considerada "la niña más bella de Cartago" (Cañas, 1979, p. 18), según lo afirma su propio padre a uno de los pretendientes de la joven.

El argumento de la comedia se construye en torno a los sucesos que marcan y determinan las relaciones de la protagonista con cada uno de sus tres pretendientes. La primera relación sobre la que se tiene noticia es la de Encarnación con el teniente José Corona, la cual se ve truncada porque el pretendiente pierde la cordura, según unos porque vio a la segua, según otros porque está embrujado y, según el padre de Encarnación, porque Corona es víctima de un mal venéreo incurable. La segunda relación amorosa se entabla entre la joven y Camilo de Aguilar, quien ha llegado a Cartago en busca de aventuras y de la mina de Tisingal. Esta relación se termina por dos razones; la primera, porque Encarnación se entera de que su pretendiente es seducido por Petronila Quesada, por lo que asume que Camilo ha sido embrujado; la segunda, porque Encarnación está convencida de que ella es la mujer más bella de Cartago y, por lo tanto, ella es la segua que enloqueció a José Corona y no quiere que lo mismo le suceda a Camilo. La tercera y última relación se da con don Félix Fernández, un hombre viejo, adinerado y ciego, con quien la joven decide casarse a pesar de no amarlo, pues ante la convicción de que ella es la segua, la ceguera de este último pretendiente la librará de ser vista por él en su proceso de transformación hacia la vejez y así se lo comunica a su padre cuando decide que será la esposa de don Félix:

ENCARNACIÓN.- Lo seré porque es ciego. Porque no me verá envejecer. Porque no verá que mis manos se marchitan y que mis cabellos encanecen. (Está como transportada) No verá que mi talle se desvanece y mis ojos se apagan. Para él seré siempre la bella niña Encarnación de los días en que tenía vista. Y seguiré siéndolo, como en un recuerdo, como en el recuerdo de los que no vuelven a saber de nosotros. No despertará una mañana para ver en su almohada un rostro nuevo, el de la segua. (Cañas, 1979, p. 56).

Antes de iniciar con la revisión de la crítica sobre La Segua, es pertinente referirnos a un elemento clave que debe considerarse con respecto a esta pieza dramática: el título, el cual suele abreviarse a su frase inicial, 'la segua', tal vez por lo extenso que resulta ser, porque en realidad está compuesto, además de esta frase inicial, por una serie de frases encadenadas que conforman una definición genérica (Genette, 2001, p. 52): 'comedia en tres actos con prólogo y estrambote inspirada en un relato de Anastasio Alfaro'.

El interés por la intitulación del texto parte de la propuesta de L. Hoeck (1981, p. 2), quien plantea que el título de un texto siempre supone sobre el lector una autoridad como programador de lectura, pues el título condensa y anuncia el asunto por tratar y programa el ejercicio de lectura; en otras palabras, según lo propone Genette (2001), el título identifica la obra, designa su contenido y atrae al lector.

Como se puede observar desde el título del texto en cuestión, se trata de una comedia, en este sentido, es comprobable como en efecto La Segua se ajusta estructuralmente, en parte, a las características básicas de la comedia nueva de la tradición literaria española. Por ejemplo, en esta comedia se representa la variedad ${ }^{1}$, al incluir personajes de diferentes estratos sociales:

1 “...aquesta variedad deleita mucho: / buen ejemplo nos da naturaleza, / que por tal variedad tiene belleza” (de Vega, 2002, vv. 178-180), según lo propone Lope de Vega en el Arte nuevo de hacer comedias en este tiempo. 
personajes del pueblo, como la india, o María Francisca Portuguesa y Petronila Quesada (la bruja y la prostituta, respectivamente), así como hidalgos, tal es el caso de Camilo de Aguilar, solo por brindar algunos ejemplos. También se ajusta a tres actos, según se estructura la comedia nueva; sin embargo, contiene 'prólogo y estrambote', modificaciones estructurales que se anuncian desde el título, precisamente porque en la estructura de la comedia tradicional no se contemplan. Por último, el hecho de que sea comedia no implica que refiera hechos estrictamente cómicos, pues en realidad en la comedia nueva se pueden representar tragicomedias o situaciones trágicas según sea el caso. Del mismo modo, pueden acabar en la dicha (final feliz) o en la desdicha (final no feliz).

Precisamente, en relación con la estructura de esta comedia, cabe considerar dos características sobre la producción dramática de Alberto Cañas que el discurso crítico señala, y que se fundamentan en la dicotomía tradicional forma / fondo. La primera que se establece es que este autor domina la técnica del drama, o sea, es conocedor de la norma (Cortés, 1989, p. 46). Respecto de esta afirmación del discurso crítico, cabe un cuestionamiento: si Alberto Cañas conoce la norma, ¿por qué razón la transgrede?

La segunda característica a la que apunta el metadiscurso sobre el teatro de Cañas corresponde a los asuntos tratados en su producción teatral, en este caso, se afirma que suele desarrollar temas sin importancia. No obstante, este mismo discurso crítico también concluye que su teatro cumple con la función referencial del texto literario, pues se ocupa de temáticas nacionales, de ahí que su producción dramática se califique como "popular", "nacional", "localista" (Cortés, 1989, p. 44); esto se ejemplifica con La Segua, texto que formó parte de los planes de enseñanza en el aparato escolar, justamente, por su carácter referencial. Entonces, parece contradictorio que se considere que la temática de su producción teatral sea de poca importancia y que aun así sea uno de los dramaturgos leídos en el sistema escolar.

De acuerdo con esta segunda característica que apunta el metadiscurso sobre la producción de Cañas, debe prestarse atención, nuevamente, al título, pues este anuncia los (pre) textos que son re-semantizados en esta pieza teatral: la leyenda de la segua, que obviamente se instaura en la frase inicial del título, y un relato de Anastasio Alfaro ${ }^{2}$, publicado en 1906 en Arqueología criminal americana (2004), en cual se inspira 'remotamente' y de cual toma dos personajes femeninos que son reelaborados en La Segua: María Francisca Portuguesa y Petronila Quesada. Según consta en el mentado relato de A. Alfaro a estas dos mujeres se les abrió una causa por brujería en el 1775 en Cartago.

En síntesis, considerados los términos en los que está planteado el título de la comedia, es posible afirmar que este funciona no solo como un mecanismo de programación de lectura, sino también como un mecanismo de dilación, pues induce al lector a una expectativa: la pieza se va a referir a la leyenda de la segua y, probablemente, el relato de Anastasio Alfaro gire en torno al mismo motivo, pero esto no sucede en el drama, pues lo que se representa es la historia particular de Encarnación Sancho, quien cree ser la segua; en este sentido, la leyenda funciona

2 En realidad, más que un relato consiste en los argumentos expuestos por el licenciado Enrique de Águila en defensa de dos jóvenes, María Francisca Portuguesa y Petronila Quesada, a quienes se les siguió una causa por hechicería que se empezó a tramitar en Cartago en setiembre de 1775. A la primera se le acusa por tener una relación ilícita con Matías Quesada y, a ambas, por brujas, pues Matías Quesada alega que una úlcera en sus partes pudendas es el resultado de un hechizo de estas mujeres. Una vez que de Águila expone sus argumentos, ambas mujeres son absueltas (Alfaro, 2004). 
como (pre)texto para el argumento de otra historia. En cuanto al otro (pre)texto, el relato de Anastasio Alfaro, se trata de un discurso de orden legal en el que un abogado argumenta las razones por las cuales las dos jóvenes acusadas de brujería deben ser absueltas y no tiene relación alguna con la leyenda.

Una vez planteadas estas observaciones, continuamos con la revisión de los estudios específicos sobre La Segua, de Alberto Cañas.

En 100 años de literatura costarricense (2018), Margarita Rojas y Flora Ovares aseguran que el teatro en Costa Rica cobra un auge en la segunda mitad del siglo XX y señalan, al igual que otros estudiosos de la literatura nacional (Cortés, 1989; Sandoval de Fonseca, 1978), que el grupo de autores que se destaca en este periodo está conformado por Samuel Rovinsky, Daniel Gallegos y Alberto Cañas. Sobre este último, afirman que en el plano argumental su teatro desarrolla, ante todo, la temática de las relaciones de pareja. Concretamente, sobre La Segua señalan que en este texto "pese a la criticidad acerca de algunos convencionalismos e instituciones sociales, el papel asociado al personaje femenino se mantiene dentro de los límites tradicionales" (Rojas y Ovares, 2018, p. 621). Como se puede colegir, las autoras intuyen un intento de crítica en el texto de Cañas, pero no explicitan qué convenciones o instituciones se cuestionan.

En el año 1975, en el segundo número de la Revista de Filología y Lingüística, Virginia Fonseca publica un artículo sobre esta pieza teatral de Alberto Cañas Escalante. En este escrito, titulado "No quiero ser segua o afán de perennidad de belleza", la autora propone un acercamiento a este drama a partir de tres códigos que, de acuerdo con su planteamiento, articulan los significados de la inclusión del motivo de la segua en la pieza teatral, estos son: el código literal, que refiere la historia amorosa de Encarnación Sancho, la protagonista; el código paralelo, que incluye el elemento maravilloso ligado a la leyenda de la segua y al elemento de la brujería; y por último, el código derivado, que refiere los recursos de la protagonista para mantener su juventud y su belleza.

Fonseca (1975) centra su atención en el código literal, es decir, en las vicisitudes de las relaciones amorosas de Encarnación con sus pretendientes, el teniente José Corona, Camilo de Aguilar y don Félix Fernández, para concluir que el fracaso de las dos primeras se debe a la superstición o a lo maravilloso, lo que se implica en el código paralelo, pues "la protagonista acepta, como justificación del suceder, que sus pretendientes y ella quedan embrujados" (Fonseca, 1975, p. 70). De esta forma, Encarnación admite creer en la brujería y, al considerarse la mujer más bella de Cartago, termina identificándose con la segua que lleva a sus dos pretendientes a perder la cordura, razón por la cual las relaciones amorosas con sus dos primeros pretendientes se ven frustradas.

En lo relativo a la relación con don Félix Fernández, con quien Encarnación se casa, Fonseca (1975) la valora a partir del código derivado y concluye que, en efecto, el único pretendiente posible para la protagonista es don Félix porque su ceguera le impedirá perder la razón, ya que no verá en su amada a la segua, pero sobre todo porque él representa el único recurso con el que cuenta Encarnación para mantener su juventud y su belleza.

El código derivado descansa sobre una relación de semejanza bajo la fórmula "como si", eje de la conducta futura de la protagonista. Encarnación decide casarse con don Félix, pues la ceguera de éste le servirá "como si" le fuera dado fijar la hermosura de sus quince años.

Los dos últimos códigos, paralelo y derivado, son los que se hallan más íntimamente ligados. Aquel se encuentra sostenido por pocos personajes, pero cobra intensidad porque tiene el soporte de la protagonista y sus conflictos. (Fonseca, 1975, p. 70). 
¿Cuál es el conflicto de Encarnación en este drama? Pues, que en efecto, está convencida de ser la mujer más bella de Cartago porque todos en el lugar así lo confirman, entre ellos su padre y sus pretendientes, incluso ella misma lo afirma cuando María Francisca le explica que José Corona enloqueció al ver a la segua

ENCARNACIÓN.- En adelante serán nuevos pájaros sobre mi vida. A José Corona le salió la segua en el camino: la más bella de todas las mujeres. Lo encantó por bella, él la siguió por bella, la quiso por bella como me quiso amar a mí, y detrás estaba el monstruo. Yo no quiero ser la segua, Manuela. Decime, Manuela, que yo no soy la segua. (Cañas, 1979, pp. 12-13).

Precisamente esta idea obsesiva de Encarnación sobre su mentada belleza y su identificación con la segua, según ella, producto de haber sido embrujada por Petronila y María Francisca, sustentan la tesis de Virginia Fonseca de que en La Segua de Alberto Cañas lo que prima es la historia de una mujer cuya vanidad y egolatría le suscitan el deseo de no convertirse en segua (de ahí el título de su artículo), en otras palabras, de acuerdo con Fonseca (1975), Encarnación pasa por un proceso de mejoramiento ya que al casarse con don Félix este nunca la verá envejecer ni verá a la segua.

En el plano de la intriga, el deseo de no convertirse en segua puede interpretarse como vanidad y aun como egolatría; pero según el código en que esto se ubique, podría mirarse como un intento de vencer los límites del hombre, de conquistar un absoluto bajo la apariencia de eterna belleza. Como el ser existencial se haya preso en la cárcel del tiempo y el espacio, para evadirse de ella tiene necesariamente que acudir a recursos sobrenaturales: evasión vertical, como la de los místicos; o a medios maravillosos de evasión horizontal. La segua ha adoptado esta última dimensión. (Fonseca, 1975, p. 71).

Aparte de esta propuesta de lectura, la autora se interesa por otros aspectos de la pieza teatral. Concretamente, se cuestiona sobre el mensaje que, por una parte, pueden recibir los personajes de la historia y, por otra, el que pueden recibir los espectadores / ¿lectores? del drama. Su inquietud radica en que, como lo indica el título de la pieza teatral: La Segua. Comedia en tres actos con prólogo y estrambote inspirada remotamente en un relato de Anastasio Alfaro, al final del texto dramático se incluye un recurso de cierre que el autor llama 'estrambote' ${ }^{3}$. En este apartado aparecen tanto personajes de la época en que se desarrolla el drama, como otros de épocas posteriores al tiempo de la historia; a saber, de 1800, de 1850, de 1910 y de 1971. Los parlamentos de estos personajes refieren diversos juicios sobre la historia de Encarnación Sancho, se trata de diversas valoraciones que estos personajes comentan sobre la historia de la joven.

Sobre esta particularidad del estrambote en La Segua de Alberto Cañas, Fonseca (1975) ofrece dos conclusiones. En primera instancia, afirma que se trata de un recurso que busca incentivar la actividad intelectual del espectador, pues es una forma de que este interprete el mundo mostrado a partir de las apreciaciones de personajes de diferentes épocas, desde las que expresan los personajes del Cartago de "mil setecientos y pico", hasta las de los estudiantes de 1971, sobre todo con las apreciaciones de estos últimos, se introduce la temática de la complejidad del mundo moderno (p. 74).

La segunda conclusión es negativa, pues cuestiona el cierre del drama y plantea que, si bien con el estrambote, como ya se ha señalado, se apela al espectador, también sirve para

$3 \quad$ Según Marchese y Forradellas, se trata de un conjunto de versos que se suman a una composición poética con forma fija y cerrada, sobre todo al soneto (2000, p. 150). 
neutralizar la tragedia que representa la muerte de Camilo de Aguilar hacia el final de la historia; no obstante, técnicamente resulta muy artificioso, ya que:

[...] la pieza no se resuelve con una sola técnica, sino que se halla dividida en dos porciones bien diferentes: la primera de ellas responde a un teatro tradicional (en el sentido de que no despierta actitud crítica); la segunda, constituida por el estrambote, busca procedimientos brechtianos. Si tal esfuerzo épico estuviese presente a lo largo de la obra y no sólo en es estrambote, éste no produciría el efecto de ser artificioso. (Fonseca, 1975, p. 74).

Como se puede constatar, la autora relaciona la inclusión del estrambote, a pesar de que lo juzga "artificioso", con una posible función ideológica del texto dramático. En este punto, vale aclarar que la lectura de Fonseca (1975) deja de lado el otro elemento estructural que no compete a la forma de la comedia: el prólogo.

Otro estudio que considera el texto de Cañas es la tesis doctoral de Manuel Martínez Herrera, Análisis hermenéutico profundo acerca de la feminidad en la leyenda "La Segua": el caso de la obra de Alberto Cañas (2012). Esta propuesta, a pesar de partir del texto de Cañas, no se ajusta a un estudio literario, pues su objetivo en relación con la pieza dramática consiste en analizar la función social y psicológica de la mujer, para esto fundamenta su estudio en el psicoanálisis y la hermenéutica profunda ${ }^{4}$; de acuerdo con Martínez

\begin{abstract}
El psicoanálisis, como hermenéutica de lo inconciente [sic.] encuentra su complemento en la hermenéutica profunda que retoma los procesos de socialización inherentes al individuo, a partir de los contextos histórico-sociales en los que éste se desarrolla [...]; lo cual, permite asimilar los aportes de las denominadas "ciencias sociales críticas", "la crítica de las ideologías" y del "interés emancipatorio". (Martínez Herrera, 2012, p. 67).
\end{abstract}

Según lo afirma el autor de esta tesis, la hermenéutica profunda, la cual se nutre del análisis freudiano y del marxismo, le permite al investigador identificar y descifrar, en el texto literario, las formas interaccionales y simbólicas que a partir de experiencias sensuales, presentativas, simbólicas y lingüísticas (re)producen, entre otras, cotidianidades pasadas, relaciones sociales, vivencias de masculinidad / maternidad y vivencias de paternidad / maternidad.

Así, con la finalidad de aplicar este método, establece el origen cultural e histórico de la leyenda de la segua, contextualiza el tiempo histórico recreado en La Segua de Cañas y las relaciones "inter-textuales" asociadas a esta, así como el contexto histórico de producción del drama en estudio, para luego analizar el concepto de feminidad que se construye en el texto. A partir del contraste y examen de todas estas variables, el autor básicamente concluye que Cañas abandona la posibilidad de construir una protagonista contestataria, acorde con las circunstancias históricas y sociales de la época en que el autor realiza el ejercicio de escritura (segunda mitad de siglo XX), y más bien opta por una Encarnación convencional, apegada a la tradición y que es, sobre todo, una hija obediente, de manera que:

[...] va a continuar siendo esclava, acaso para siempre, de la mirada masculina. Porque aún, cuando hablamos del derecho del autor a decidir las características y el destino de sus personajes, echamos de menos elementos dramáticos y narrativos, a partir de los cuales el lector pudiera dar una segunda mirada, quizá crítica, de lo sucedido. (Martínez Herrera, 2012, p. 220).

Apoyándose en este abordaje del texto de Cañas, Martínez asegura que en La Segua se muestra una conformidad político-social con las condiciones socio-culturales en que vivían las

Método de análisis, expuesto inicialmente por Alfred Lorenzer (Escuela de Frankfurt), que propone una reformulación metateórica y se plantea la indagación de la dimensión social de lo inconsciente presente en el encuentro del sujeto con la cultura (Martínez Herrera, 2012, p. 70). 
mujeres durante la colonia en Costa Rica. Además, agrega que Cañas no se preocupa por las condiciones históricas en las que se desarrolla el drama, sino que solo 'explota' la circunstancia particular de Encarnación; a saber, su caso de "narcisismo femenino", por lo que ambientar la historia en la colonia es:

mero pretexto y artilugio [...], al igual que lo es la leyenda para justificar el delirio del personaje principal. No se puede descartar que algún tipo de concepción patriarcal obturara una comprensión más integral y crítica de la realidad parte del autor [sic.] [...], quien a pesar de estar inmerso en los profundos cambios políticos y sociales de su tiempo, no ubica la problemática contemporánea e histórica de la mujer en su obra, asignándole sin más, un papel tradicional y subalterno. (Martínez Herrera, 2012, p. 221).

Como ya se ha indicado, esta propuesta de Martínez dista de ser un análisis literario de La Segua, y tampoco lo pretende, pues en primer lugar considera que el texto literario es un dato socio-histórico, con un valor documental y, a partir de esta asunción, determina que el concepto de feminidad que Cañas presenta en La Segua es 'tradicional ' y 'subalterno', tal cual lo debe haber sido durante la colonia en el Cartago del siglo XVIII (podría agregarse, también, que tal y como se plantea en la leyenda misma). Más aun, cuestiona que siendo Cañas un autor de la segunda mitad del siglo XX no subvierta este concepto 'tradicional' de feminidad en su ejercicio de escritura, por lo que sugiere que "algún tipo de concepción patriarcal" del autor impide el cambio en el modelo de feminidad de este drama.

Desde la perspectiva de la teoría literaria, la principal crítica a esta conclusión de la propuesta de Martínez se fundamenta en que el texto literario es, ante todo, ficción, una representación no especular de un segmento de la realidad, elaborada o recreada, por un sujeto cultural. Además, en el caso de La Segua de Cañas esto se complica porque la historia ficticia, el mundo mostrado en ella, si bien se ambienta en el siglo XVIII, es la propuesta de un sujeto cultural de la segunda mitad del siglo XX, lo cual no es aval para garantizar la representación de una feminidad no 'tradicional' que difiera de la que determinó la vida de la colonia en el Cartago del siglo XVIII (sobre todo si se considera el principio de verosimilitud), como tampoco puede afirmarse que la representación de la feminidad que elabora Cañas sea exactamente la misma que se concebía en el siglo XVIII.

En resumen, Rojas y Ovares (2018), Fonseca (1975) y Martínez (2012), coinciden en que la protagonista de La Segua se representa dentro los límites tradicionales del rol femenino. Fonseca (1975) y Martínez (2012) llegan a esa conclusión porque consideran la leyenda de la segua como el sustrato, no re-semantizado, que cimienta no solo las peripecias de la historia de Encarnación Sancho, sino también el modelo de feminidad al que se ajusta la protagonista. Obviamente, estas propuestas se fundan en una programación de lectura inducida por la frase inicial del título: 'la segua'.

Nuestra propuesta de lectura parte, en primera instancia, de que La Segua de Alberto Cañas ofrece una historia particular y diferente de la que se narra en la leyenda popular (aun considerando las diversas versiones), esta historia particular es la de Encarnación Sancho y su singular devenir. De manera que no se pretende fundamentar nuestra lectura en los (pre)textos; sin embargo, sí se basará en los dos elementos estructurales que se incluyen en la definición genérica del título de la comedia: el prólogo y el estrambote. La razón para esto reside en demostrar que en La Segua de Alberto Cañas predomina el género discursivo del chisme como un mecanismo no solo de identificación grupal, sino también como discurso contestatario que socava la institucionalidad del discurso del pasado histórico de la colonia. 
A continuación, se expondrán algunas consideraciones teóricas en las que se fundamenta nuestra propuesta de lectura, así como las características generales y las principales funciones del chisme en tanto género discursivo.

Primero nos referiremos al concepto de enunciado expuesto por M. Bajtín en "El problema de los géneros discursivos" (1985). De acuerdo con este teórico, la unidad real del proceso de la comunicación discursiva es el enunciado, en el cual se articulan de manera indisoluble el contenido temático, el estilo y la composición. Esto se aplica a todo enunciado, ya sea este una respuesta breve en la interacción en un diálogo cotidiano, un tratado científico o un texto literario (Bajtín, 1985, p. 260). Afirma, además, que cada enunciado es individual, pero según el uso que se haga de la lengua en él, se elaboran enunciados relativamente estables a los que denomina géneros discursivos, por ejemplo, entre otros, se consideran como géneros discursivos un diálogo cotidiano, una orden militar, una carta, los géneros literarios, el chisme.

De lo anterior se desprenden dos ideas fundamentales; la primera, concibe el texto literario como un enunciado; la segunda, en tanto enunciado, implica o supone un proceso de comunicación. Aunado a esto, Bajtín subraya que todo enunciado es precedido por los enunciados de otros y, a la vez, le suceden enunciados-respuesta de otros, a partir de esto, afirma que todo texto literario entra en una relación dialógica con otros textos. Además, Bajtín propone que el texto literario al incorporar otro texto en su interior, lo hace desde una posición ideológica determinada; es decir, el texto citado es susceptible de ser re-semantizado.

Otros conceptos considerados en nuestra propuesta los expone Yuri Lotman en Estructura del texto artístico (1982). Este semiólogo conceptualiza el arte como un sistema modelizante secundario que se sirve de una lengua natural en tanto sistema de comunicación; es decir, "el arte puede describirse como un lenguaje secundario, y la obra de arte [el texto literario, en este caso] como un texto en este lenguaje" (Lotman, 1982, p. 20). A partir de este postulado afirma, entonces, que en el peculiar lenguaje del arte la idea poética es indivisible de la estructura que toma el texto.

\footnotetext{
Al examinar la estructura de las naturalezas semiológicas, se puede hacer la siguiente observación: la complejidad de la estructura es directamente proporcional a la complejidad de la información transmitida. La complicación del carácter de la información conduce inevitablemente a una complicación del sistema semiológico empleado para su transmisión. Además, en un sistema semiológico correctamente construido (es decir, que alcance el objetivo para el cual ha sido creado) no puede haber una complejidad superflua, injustificada. (Lotman, 1982, p. 21).
}

Como se puede concluir, estos teóricos coinciden en conceptualizar el texto literario como un fenómeno comunicativo en el que se realiza un proceso de elaboración o de re-creación con el lenguaje, en esta producción de sentidos "el carácter de la información” o contenido temático determina cómo se construye el "sistema semiológico" con el cual se quiere transmitir la información.

Seguidamente, para efectos de este artículo consideramos algunas de las características básicas del chisme según las expone Fabiola López Rodríguez en "Antecedentes teóricos del chisme" (2015). Si bien algunos investigadores parten de la idea de que no existe diferenciación alguna entre chisme, rumor y escándalo, hay otros que sí las establecen. De acuerdo con López (2015), el chisme es una práctica comunicativa cotidiana que se lleva a cabo con mucha frecuencia en encuentros sociales, sean estos planeados o no. Suele darse en "conversaciones casuales que giran en torno a terceras personas en el momento de la interacción" (López, 2015, p. 93), en este sentido, el chisme se considera una conversación evaluativa en la que se relatan hechos (sean verdades, mentiras o versiones exageradas) sobre terceras personas. 
Desde la antropología el chisme se considera como una forma en que los sujetos conciben el mundo y la vida en sociedad, además, su rol en la comunicación es clave porque contribuye a generar la cohesión grupal y la identificación entre los sujetos, pues afianza grupos sociales, en tanto chismear "es al mismo tiempo un privilegio y un deber, te ratifica como miembro de un grupo, pero a la vez te exige que lo practiques a fin de no perder la membresía" (2015, p. 96), esto porque se transmite entre sujetos que comparten una historia e intereses en común. En resumen, de acuerdo con López (2015), el chisme es una interacción oral cara a cara, no suele ser anónimo (como sí lo es el rumor), es una práctica colectiva y tiene una función marcadamente valorativa.

Establecidos los anteriores conceptos y, tal como se planteó anteriormente, la intención de centrar nuestro ejercicio de lectura en los dos elementos estructurales que se anuncian en el título de esta pieza dramática se justifica en tanto permite establecer qué función cumplen el prólogo y el estrambote en el proceso comunicativo que esta producción de Cañas representa, pues como se ha aclarado, si el asunto temático determina la estructura que toma el texto, ¿qué información nos brindan estos apartados?

Primeramente, ¿qué es un prólogo? El prólogo es el texto que precede al cuerpo de una obra, puede haber sido escrito por el autor o por otro escritor, en principio se utiliza para presentar la obra, para justificarla o para hacerla más comprensible al lector. En el teatro griego clásico consistía en el apartado que precedía a la primera participación del coro, en él se exponía información necesaria para que los espectadores comprendieran la representación. También funcionaba como medio para conseguir la integración del espectador en la representación, o también para que mantuviera cierta distancia con lo representado. En el teatro isabelino, como lo afirma Borges en Prólogos con un prólogo de prólogos (1975), el prólogo era el actor encargado de presentar el tema del drama, de manera que la función de este apartado no debe subestimarse, sobre todo en el teatro, pues forma parte de la representación y cumple con la función de captar la atención de los espectadores. Como bien lo expresa Borges en el documento ya citado: "El prólogo, cuando son propicios los astros, no es una forma subalterna del brindis; es una especie lateral de la crítica" (Borges, 1975, p. 10).

A continuación, se transcribe el íncipit ${ }^{5}$ del prólogo de La Segua, no sin antes tomar en cuenta algunas acotaciones planteadas en la didascalia inicial del texto. Según se indica en esta, la escena se ubica en la calle frente a la casa de don José Manuel Sancho de Castañeda, el padre de Encarnación. También se indica que en ella interactúan "caballeros y damas de pretensión señorial; vecinos nobles y leales de Cartago, respetables y serios. Pasan lentamente y conversando" (Cañas, 1979, p. 9).

FRAY DIEGO.- De manera que es de hoy a mañana que esperan a don Félix.

DON RAFAEL DE SOTOMAYOR.- De hoy a mañana.

DON EUSTAQUIO DE NAVA.- Es el mismo don Félix Fernández que fue Receptor de Alcabalas.

DOÑA ROSALÍA DE SOTOMAYOR.- El mismo. Que regresa después de una ausencia de ocho años.

DON TOMÁS PERALTA.- Dicen que es hoy hombre rico.

LA INDIA.- (Acercándose al grupo) Si está rico, ¿por qué querrá regresar a Cartago?

DON RAFAEL.- Dicen, además, que viene enfermo.

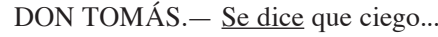

5 "Técnica de análisis propuesta por Duchet, basada en la teoría de que el comienzo de un texto es un lugar estratégico de condensación de sentido. Desde el arranque, el texto organiza una serie de códigos que pueden orientar la lectura" (Amoretti, 1992, p. 66). 
FRAY DIEGO. - ¿Ciego? ¿Rico y ciego?

DON TOMÁS. - A veces es lo mismo... (Cañas, 1979, pp. 9-10, el subrayado es nuestro).

Como se puede observar, ya desde este exordio se instaura un ambiente en el que se da una relación de cuentos o chismes en torno a terceras personas, en este caso concreto, nótese que quienes comentan el regreso de don Félix a Cartago son identificados con nombre y apellido, incluso entre ellos se encuentra un religioso. Nótese también el uso de formas verbales impersonales: "dicen", "se dice", lo que nos permite señalar que la fuente de la información no es conocida. Se indica también en un tono irónico que son "respetables y serios" (Cañas, 1979, p. 9), sobre todo si consideramos que están chismeando, y se trata de "vecinos nobles y leales de Cartago" (Cañas, 1979, p. 9), haciendo alusión al tratamiento de la "muy noble y muy leal" otorgado a la ciudad por las Cortés de Cádiz en 1814.

Esta introducción del género discursivo del chisme desde el prólogo funciona como enganche para captar no solo la atención del espectador / lector, sino también para despertar su interés en saber quién es don Félix y por qué si es adinerado y está enfermo regresa a Cartago, según lo plantea el único personaje que no se identifica con nombre y apellido: "LA INDIA.- (Acercándose al grupo) Si está rico, ¿por qué querrá regresar a Cartago?” (Cañas, 1979, p. 9), pues al introducirse este cuestionamiento, el espectador / lector se ve inmerso en la chismografía (para hacer uso del término coloquial) de la historia que será representada, pues, indudablemente, ante la interrogante de la india, el asunto es saber qué sucede en Cartago, por qué no es considerado por este personaje como un buen lugar.

Siempre en relación con la apreciación valorativa que implica la participación de la india, en la segunda didascalia de este prólogo, en la que se introduce a los personajes de Encarnación Sancho y Manuela, la acotación indica lo siguiente: “...entran Encarnación Sancho y Manuela. De Encarnación se afirma que es la mujer más bella de la ciudad, y bien podría serlo. Manuela le hace de dueña, pero esta no es ciudad de dueñas..." (Cañas, 1979, p. 10, las cursivas son del texto, el subrayado es nuestro). En primera instancia, como se puede apreciar, al decir que Cartago no es ciudad de dueñas, se nos brinda información sobre las condiciones sociales del lugar, pues recordemos que una acepción en desuso del sustantivo 'dueña' es la de 'aya', por demás, una mujer con autoridad para ejercer el cuidado de sus pupilos, condición que Manuela no cumple. Así, al afirmarse que Cartago no es ciudad de dueñas, se demerita el rol de Manuela como la encargada de guardar o cuidar de Encarnación, pero también se da información sobre la sociedad cartaginesa. En segundo lugar, el empleo, nuevamente, de formas verbales impersonales ("se afirma") y el uso del condicional ("podría") siguen reforzando la idea de que todo lo que se refiere en esta historia es producto de la murmuración.

En efecto, todos los aconteceres de La Segua, de Alberto Cañas, deben entenderse y comprenderse dentro del género discursivo del chisme, nada de lo representado o comentado en el drama es absolutamente comprobable en la historia misma. Por ejemplo, en el primer encuentro entre Camilo de Aguilar y don José Manuel Sancho, este se encarga de aclararle al nuevo pretendiente de su hija que en relación con lo sucedido a José Corona se han dado varias explicaciones, pues según él, tiene noticia de que "cuantos sabían de las amistades nocturnas que [Corona] frecuentaba, llegaron a la conclusión de que había sido hechizado por una Petronila Quesada...” (Cañas, 1979, p. 19), a lo que Camilo responde: "Sí, por las calles circula esa versión, y todos la dan por cierta” (Cañas, 1979, p. 19). No obstante, también corre el rumor de que Corona enloqueció debido a su encuentro con la segua, pero don José Manuel también 
tiene su versión para explicar la condición de este personaje, la cual, dicho sea de paso, nunca se comprueba en la historia: "JOSÉ MANUEL.- [...] La verdad la ha dicho el facultativo en medicina que ha venido de Nicaragua y examinado a José Corona: la segua del teniente es un mal venéreo incurable" (Cañas, 1979, p. 19).

En los mismos términos se plantea la condición de Encarnación, hay quienes creen que está embrujada, como se lo comunica Manuela a fray Diego: "La niña Encarnación está embrujada padre, yo sé por qué se lo digo" (Cañas, 1979, p. 39), y que de hecho es lo que se murmura en la ciudad. Sin embargo, para fray Diego no se trata de un embrujo sino de un trastorno mental. Una vez más, ninguna de las dos posibles causas de la condición de la protagonista se comprueba, todo se maneja en el ámbito de la murmuración y del chisme.

En fin, los hechos representados en La Segua se enmarcan en el ámbito de lo no comprobable, se dice que el teniente Corona está embrujado, que vio a la segua; se dice que Encarnación está trastornada, que está embrujada; se dice que María Francisca y Petronila son brujas, ellas lo niegan a pesar de la escena en la que realizan un conjuro para 'ligar' a Camilo de Aguilar, de hecho, María Francisca ya ha sido absuelta de este cargo. Más aún, toda la información en la ciudad de Cartago se transmite oralmente, como se puede comprobar en la escena sétima del segundo acto cuando Baltasara, la esposa de don José Manuel, a la llegada de este a la casa, le pregunta: “Qué noticias traes de fuera?” (Cañas, 1979, p. 45) e inmediatamente él refiere que ha habido un nacimiento y que se espera la visita del Obispo Tristán.

Todo en esta ciudad de Cartago es producto de los decires de sus habitantes, nada de lo que sucede se somete a comprobación alguna, de hecho, se cuentan versiones diferentes para cada evento o condición de los personajes. Esta singularidad de la historia cobra fuerza hacia el final cuando Petronila Quesada asesina a Camilo, y al encontrar el cadáver todos asumen que se trata de un suicidio y lo único que acuerdan los personajes que dialogan, precisamente los mismos que participan al inicio en el prólogo, es no decir nada de esto a Encarnación, quien para ese momento ya se ha casado con don Félix y se disponen a viajar a Guatemala.

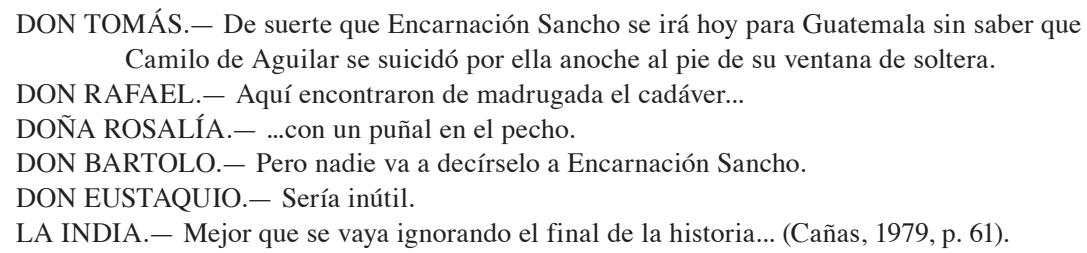

Inmediatamente después de este diálogo, se introduce el estrambote con que se cierra el texto dramático. El estrambote es una forma menos común que el prólogo y según lo explican Marchese y Forradellas (2000) consiste en una serie de versos que se añaden a una composición poética que presenta una forma fija y cerrada, como el soneto, y su función suele ser humorística. Además, en el Diccionario de la Real Academia se explica que la palabra 'estrambote' procede del italiano strambotto que significa 'extravagante', 'irregular', 'sin orden' (2001, p. 1002).

En efecto, el cierre de esta comedia resulta irregular, pues en el estrambote se incluyen una serie de personajes que expresan sus opiniones acerca de la historia de Encarnación. Los dos primeros son parte del grupo de "serios y respetables" vecinos de Cartago, coetáneos de los personajes de La Segua, se trata de don Rafael y don Eustaquio, quienes comentan que don José Manuel 'vendió' a su hija al pretendiente adinerado para resolver sus problemas financieros. Luego aparecen dos personajes femeninos de 1800, madre e hija, la primera 
comenta que Encarnación fue obligada a casarse con un hombre viejo y su amante murió de amor al pie de su ventana. Después de esta intervención entran dos caballeros de 1850, uno de ellos descendiente de la familia Sancho. En su diálogo aseguran que don José Manuel obligó a su hija a casarse con un viejo, rico y noble para mejorar la estirpe y que el fantasma del padre aparece en la casona. Se presentan luego dos caballeros de 1910, uno de ellos asegura que en los Archivos Nacionales hay pruebas de que Encarnación y Camilo tuvieron relaciones ilícitas; el segundo, otro descendiente de los Sancho, se ofende y reta a duelo al primero. Finalmente, aparecen dos estudiantes de 1971; el primero pregunta qué importancia tiene la historia de una narcisista como Encarnación; el segundo responde que en 1971, con los problemas del mundo, la historia de Encarnación no es importante.

Es precisamente este estrambote y la participación de los personajes que en él aparecen, lo que Virginia Fonseca (1975) califica como un fallo técnico, pues además de que estructuralmente transgrede la forma tradicional de la comedia, considera los parlamentos de los personajes como 'elementos brechtianos' que Cañas introduce, exclusivamente, en este cierre para increpar al espectador / lector de la comedia y hacerlo reflexionar sobre lo representado en el drama.

Nuestra posición en cuanto a la inclusión del estrambote y su función en esta comedia difiere de la expuesta por Fonseca (1975). Para empezar, recordemos que según lo plantea Lotman, en el texto literario la idea poética es indivisible de la forma que toma el texto. En el caso de la comedia en cuestión, ya desde el título, en la definición genérica (Comedia en tres actos con prólogo y estrambote...), se anuncia que la pieza dramática ofrece una particularidad estructural, la inclusión de un prólogo (que Fonseca no considera en su propuesta) y un estrambote. En este sentido, partiendo de que en el texto literario nada es arbitrario, baste con recordar que el prólogo en tanto programador de lectura cumple, en esta comedia en particular, con la función de introducir al espectador / lector en el ámbito del chisme, género discursivo que predomina y determina la idea poética en esta comedia, pues como ya lo hemos demostrado, nada de lo que se representa en ella es comprobable. Siguiendo a Borges, este prólogo no es una forma subalterna, y por extensión podemos afirmar que tampoco lo es el estrambote en el cierre del mundo mostrado, pues si el prólogo condensa y anuncia la murmuración como la tónica de la historia representada, el estrambote no solo lo refuerza, sino que favorece que los chismes trasciendan a lo largo de diversas épocas, como una suerte de teléfono roto que pone en tela de juicio la veracidad del discurso del pasado, ya que como vemos, en La Segua de Alberto Cañas todo evento tiene dos o más versiones, cada personaje expresa su opinión sobre otros personajes y esto llega al extremo en los parlamentos de los personajes que aparecen en el estrambote.

En conclusión, ambos recursos, más que increpar al espectador / lector para que este reflexione en términos generales sobre la complejidad del mundo moderno, según lo propone Fonseca con respecto al estrambote (1975, p. 74), apelan, en una primera instancia, al sentido de cohesión grupal, de identificación con una comunidad, lo cual se logra con la representación de una ciudad de Cartago en la que predomina el chisme; en relación con esta propuesta, recordemos la importancia que el discurso histórico oficial o el género discursivo de la Historia le otorga a esta ciudad por haber sido la capital de la provincia durante la colonia y luego haber sido la primera capital de Costa Rica. En una segunda instancia, al incorporar en la comedia el chisme como recurso discursivo se evidencia la función contestataria en relación con el discurso tradicional. 
En otras palabras, el prólogo y el estrambote conforman y evidencian el ámbito de las murmuraciones y de los chismes que caracterizan las coordenadas espacio-temporales en esta comedia, a la vez que con esta representación particular de la Cartago de "mil setecientos y pico", contribuyen con la deconstrucción del discurso oficial sobre "la muy noble y muy leal ciudad de Cartago", con lo cual se pone en tela de juicio la institucionalidad del discurso (¿histórico?) del pasado.

\section{Bibliografía}

Alfaro, A. (2004). Arqueología criminal americana. San José: Editorial Jurídica Continental.

Amoretti, M. (1992). Diccionario de términos asociados en teoría literaria. San José: Editorial de la Universidad de Costa Rica.

Bajtín, M. (1985). El problema de los géneros discursivos. En Estética de la creación verbal (pp. 248-293). México: Siglo Veintiuno Editores.

Borges, J. L. (1975). Prólogos con un prólogo de prólogos. Madrid: Alianza Editorial.

Cañas, A. (1979). La Segua. Comedia en tres actos con prólogo y estrambote inspirada remotamente en un relato de Anastasio Alfaro. San José: EDUCA.

Cortés, M. L. (1989). Hacia una problemática del metadiscurso dramático: Cañas, Gallegos y Rovinsky. Revista de Filología y Lingüística de la Universidad de Costa Rica, 15(1), 41-54.

De Vega, F. L. (2002). Arte nuevo de hacer comedias en este tiempo. Recuperado de http://www.cervantesvirtual.com/obra-visor/arte-nuevo-de-hacer-comedias-en-estetiempo--0/html/ffble6c0-82b1-11df-acc7-002185ce6064_4.html

Fonseca, V. (1975). No quiero ser segua o afán de perennidad de belleza. Revista de Filología y Lingüística de la Universidad de Costa Rica, 1(2), 69-74.

Genette, G. (2001). Umbrales. México: Siglo Veintiuno Editores.

Hoeck, L. (1981). La marque du titre. Dispositifs sémiotiques d'une pratique textuelle. Paris: Mouton.

López, F. E. (2015). Antecedentes teóricos del chisme. En G. Gutiérrez, G. Mugford y R. Yáñez (Eds.), Argumentación discursiva en textos orales y escritos (pp. 93-114). México: Universidad de Guadalajara.

Lotman, Y. (1982). Estructura del texto artístico. Madrid: Ediciones Istmo.

Marchese, A. y Forradellas, J. (2000). Diccionario de retórica, crítica y terminología literaria. Barcelona: Editorial Ariel.

Martínez, M. (2012). Análisis hermenéutico profundo acerca de la feminidad en la leyenda "La segua": el caso de obra de Alberto Cañas. (Tesis doctoral). Universidad de Costa Rica.

Real Academia Española. (2001). Estrambote. En Diccionario de la Lengua Española (p. 1002). Madrid: Espasa-Calpe.

Rojas, M. y Ovares, F. (2018). 100 años de literatura costarricense. (Tomo II). San José: Editorial Costa Rica.

Sandoval de Fonseca, V. (1978). Resumen de literatura costarricense. San José: Editorial Costa Rica. 
